\title{
Improving the efficiency and sustainability of disinfection at a small rural water treatment plant
}

\author{
MNB Momba ${ }^{1 *}$, N Makala $^{1}$, Z Tyafa $^{1}$, BM Brouckaert ${ }^{2}$, CA Buckley ${ }^{2}$ and PA Thompson ${ }^{3}$ \\ ${ }^{1}$ Biochemistry and Microbiology Programme Unit, University of Fort Hare, P/Bag X1314, Alice 5700, South Africa \\ ${ }^{2}$ Pollution Research Group, School of Chemical Engineering, University of KwaZulu Natal, Durban 404, South Africa \\ ${ }^{3}$ Umgeni Water, PO Box 9, Pietermaritzburg 3200, South Africa
}

\begin{abstract}
The Alice Water Treatment Plant (AWTP) has several operating problems, which often result in poor turbidity removal and inadequate disinfection residual. Some progress has been made in upgrading the skills of plant operators, but the plant performance has failed to improve because of faulty equipment, a shortage of maintenance staff and treatment chemicals that are not delivered in time. The coagulant-dosing pump was found to be malfunctioning for an extended period of time resulting in overdose problems. The self-backwashing filters were no longer backwashing as per design and were producing poor quality filtrate. This in turn increased the chlorine demand and combined with frequent failure of the chlorinators, the plant was producing poor microbiological quality final water. The storage system in the bulk distribution system was investigated and it was found that adequate chlorine residual could be achieved, provided the plant problems were rectified. The difficulties experienced in training and retaining adequately skilled people to run water treatment plants in impoverished rural municipalities have been among the major hurdles to providing acceptable water services in these areas. However a partnership between the Universities and the AWTP came up as a possible solution to these problems. It is therefore recommended that rural municipalities consider this approach and strengthen this relationship, as it played a large role in plant improvement
\end{abstract}

\section{Introduction}

The proper maintenance and operation of water supply, treatment and distribution systems is an essential part of any effort to ensure the on-going production and delivery of the highest quality drinking water possible. If a community fails to recognize the need for training and certification of operators in specific treatment processes, professional guidance and technical assistance in system selection, and adequate funding for operation and maintenance, system operation and water quality will suffer (Swartz, 2000).

Recent studies (MacKintosh and Colvin, 2002; Momba et al., 2003b; Momba et al., 2002) have shown that the majority of small water works in South Africa have difficulty providing adequate treatment and disinfection with the result that consumers are at risk of waterborne diseases even from treated water supplies. Both technical and human factors have been reported to be the major causes of the failure of small rural water treatment plants to provide potable water to their consumers. The Alice Water Treatment Plant (AWTP) is one of such small water treatment plants in the Eastern Cape Province that do not produce safe potable water. Preliminary studies performed by Muyima and Ngcakani in 1998 and by Momba and co-workers in 2002 (Momba et al., 2002) indicated that the Alice drinking water was generally of poor quality.

Since June 2002, researchers from the Universities of Fort Hare and Kwazulu Natal and Umgeni Water have been investigating the causes of inadequate disinfection at the AWTP. The study was designed to look at efforts being made to improve water treatment and disinfection practices for the water supply to the town of Alice through the development of a partnership between researchers at

This paper was originally presented at the 2004 Water Institute of South Africa (WISA) Biennial Conference, Cape Town, South Africa, 2-6 May 2004.

* To whom all correspondence should be addressed.

唺+2740 602-2365; fax: +2740 602-2429; e-mail: MMomba@ufh.ac.za the University of Fort Hare and the Nkonkobe Municipality. In the first phase of the study (September 2002-January 2003), several possible causes of inefficient disinfection of the treated water were identified. These included poor dosing of coagulant and chlorine and excessively long storage times for water in some parts of the distribution system (Momba et al., 2003a). The microbiological quality of the finished water from the AWTP (Momba et al., 2003a) and of samples drawn at various points in the distribution system (Momba et al., 2003b) generally did not meet South African Guidelines for drinking water (DWAF, 1996). Various potential pathogenic microorganisms such as Escherichia coli, Aeromonas hydrophila, Salmonella arizonae, Vibrio fluvialis, Serratia odirifera, Serratia liquiefaciens, Serratia marsecens,Pseudomonas fluorescens and Pseudomonas aeruginosa were identified from the water samples collected in the on-site reservoir (Momba and Kaleni, 2002) and various points in the distribution systems (Momba et al., 2003b). There was a possibility of the occurrence of the Vibrio at the Victoria East Clinic (one of the sites in the distribution system).

The second phase of the project (April 2003-November 2003) concentrated on two issues/activities, firstly establishing the relationship between the plant dosing system performance and the water quality in the bulk distribution system and secondly transferring knowledge and skills to the operators and the Municipality staff to ensure improved operation of the plant can be sustained in the future. Booster chlorination and lowering the operating levels of the treated water reservoirs were considered to ensure adequate chlorine residual is maintained throughout the distribution systems.

\section{Description of the plant}

The Alice plant is a conventional water treatment plant, which includes coagulation, flocculation, sedimentation, rapid sand filtration and chlorination. The design capacity of the plant is 
$7 \mathrm{M} \ell / \mathrm{d}$, however it is currently operating between 3-4 M $/ \mathrm{d}$. A number of surrounding villages currently without water services are to be connected to the Alice system in the near future. Water is drawn from the Binfield Dam on the Tyume River. At from the beginning of the investigation (June 2002) until November 2002, lime and alum were used for the pre-treatment of raw water. Ultrafloc replaced granular alum and hydrated lime at the beginning of December 2002. The coagulants were dosed at the same point just ahead of a $90^{\circ} \mathrm{V}$-notch weir and hydraulic jump. Flash mixing at the hydraulic jump is followed by a hydraulic flocculation and horizontal flow sedimentation tanks. The clarified water is the filtered through three valveless, self-backwashing filters. Chlorine gas is added to the combined filtrate just before the on-site reservoir from where it is fed into the bulk distribution system.

\section{Water quality and treatment plant operating problems in Alice during the first phase of the study}

The first phase of the investigation revealed that the AWTP's major operating problems include: 1) no flow measurement, 2) nor turbidity or $\mathrm{pH}$ measurement and no record of chlorine residual, 3) poor coagulant dosing control resulting in inadequate turbidity removal in the clarifiers and filters; and 4) a lack of a proper chlorine dosing procedure and monitoring programme. Due to inadequate pre-treatment and insufficient chlorine residuals, Alice treated water did not meet the minimum limits for potable water (Momba et al., 2003a; b). The conclusions and recommendations arising from the first phase of the study were presented to the Nkonkobe Local Municipal Water Authority. Nkonkobe was informed that although the AWTP was not operating effectively, it has great potential for improvement. This could be easily achieved minimum cost if the plant had better trained personnel.

The following was strongly recommended:

- Training of the plant operators.

- Plant flow rate - The existing non-functional raw water flow meter should be repaired or replaced and the flow rate measurement be done without fail.

- Coagulant dose rate - The treatment plant should acquire a jar testing apparatus to determine the optimum alum and lime doses. The doses should be adjusted appropriately when the raw water flow was changed. This would have reduced their coagulant costs by up to $75 \%$.

- $\mathrm{pH}$ measurement- the operators should be monitoring $\mathrm{pH}$ at various points in the plant for coagulation control.

- Turbidity measurement - the turbidity of the raw, settled, filtered and final should be monitored

- Filtration - The operators must aim for filtrate turbidity $<1 \mathrm{NTU}$ since high turbidities exert high disinfectant demand, and particles may shield microorganisms from disinfectants. Times of filter backwashes must be recorded to ensure the filters were functioning correctly.

- Disinfection-The chlorine dose has to be ratioed to the plant flow rate. To have effective disinfection, measurement of the chlorine demand of water was highly recommended.

- A monitoring programme of the bacterial quality of water at the point of treatment and various sites of the distribution systems has to be established.

By the end of November 2002, the Municipal Mentoring Programme (MMP), an agency working with local municipalities, began working with the operators and training them in the basic concepts of water treatment. A turbidimeter and a chlorine meter were provided, performance goals were set and the operators began monitoring turbidity removal and chlorine residual. They were also taught to initiate manual backwashing of the filters if turbidity breakthrough was observed. However, the training did not include flow measurement or quantitative procedures for setting the chlorine or coagulant doses, even after a new raw water flowmeter was installed.

\section{Operating conditions at the AWTP during the second phase of the study}

Despite the improvement in operator skills, the treatment plant continued to experience severe problems in the second phase of the project. Upon further investigation, it was found that these problems were mainly related to malfunctioning equipment and to stocks of treatment chemicals not being replenished in time. Contributing factors were insufficient maintenance personnel and technical expertise, and poor planning in the purchase and delivery of treatment chemicals. The continued lack of flow measurement was also a major problem.

\section{Flow measurement}

Although a functioning raw water meter was installed at the plant, it was not easily accessible and the operators had not been trained to read it. The operators change the plant flowrate as often as once a day to maintain the level in the on-site reservoir within a certain range. In order to adjust the chemical doses in proportion to the flow, they needed to know what the initial and final raw water flows are.

\section{Coagulant dosing}

Two major problems affecting the coagulant dosing were identified. Firstly, no procedures pertaining the ordering and delivery of chemicals exist in the AWTP. It takes several days or weeks for the chemicals to be delivered to the plant when they are exhausted. Throughout the waiting period the plant is run without any coagulant. Secondly, the dosing pump had apparently been struck by lighting and fine control no longer worked. Consequently, the dosing rate could not be adjusted and Ultrafloc was being overdosed. The operators were partially aware of the problem but nothing had been done about it. A jar test conducted on the $19^{\text {th }}$ November indicated that the optimum dose was around $6 \mathrm{mg} / \ell$ with acceptable turbidity removal up to about $11.5 \mathrm{mg} / \ell$. The measured dosing rate was $39.5 \mathrm{~kg} / \mathrm{d}$. Raw water flowrates for the week ranged between 3.6 and $4.8 \mathrm{M} \ell / \mathrm{d}$. At a $4.8 \mathrm{ML} / \mathrm{d}$ flowrate, $39.5 \mathrm{~kg} / \mathrm{d}$ of coagulant corresponds to a dose of $8.3 \mathrm{mg} / \ell$ while at $3.6 \mathrm{ML} / \mathrm{d}$ the dose increases to $11 \mathrm{mg} / \ell$. This means that 30 to $45 \%$ of the Ultrafloc was being wasted.

\section{Filtration}

The AWTP has been experiencing problems with its filters since at least June 2003. Throughout the second phase, the filtrate turbidities were very poor, often between 4-5 NTU and often worse than the settled water turbidity. The filters rarely backwashed autonomously, and the operators had resorted to backwashing them manually once a day. However, the initiation of manual backwash has become very slow on one filter and in November, had ceased to work at all for another. The filters had been operating for about three years.

Many small treatment plants have installed valveless filters believing that they will operate without any maintenance for many years. This belief is unfounded. Although it is true that these types 


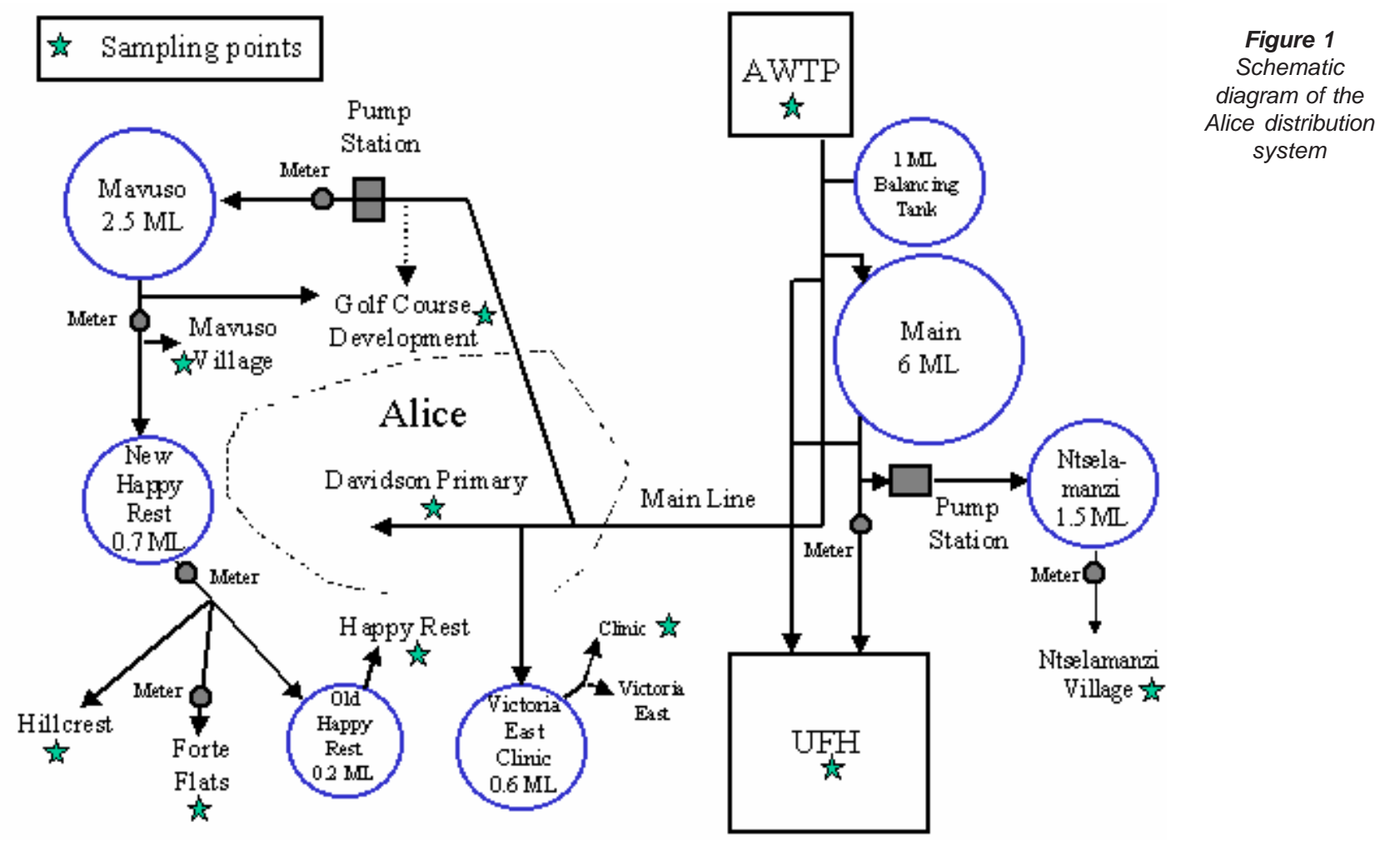

of filters typically require less maintenance than other types, research carried out by Umgeni Water has indicated that problems can be expected to develop within as a little as a year depending on the operating conditions (Brouckaert et al., 2002). The major weakness of valveless filters is that while backwash is regular when the filters are functioning properly, it is relatively inefficient. This means that over time, mud and floc will builds up in the filters, eventually causing performance problems. Long delays between backwashes, overdosing coagulant and the use of organic coagulants (Ultrafloc has an organic component) would tend to accelerate the deterioration (Brouckaert et al., 2002). The accumulated mud tends to shrink, causing cracks to form between the bed and the filter walls. As a result, influent can bypass the media resulting in poor filtrate turbidity.

\section{Chlorination}

Chlorine dosing was major on-going problem at AWTP. Delivery of chlorine gas to the plant was often delayed and the chlorinator was frequently shut down due to gas leaking from the regulator. When this happened, the Nkonkobe maintenance team was informed but it was often days or weeks before the problem was attended to. In the meantime, the plant either ran with no chlorine at all or the operators would add four HTH tablets once a day to the on-site reservoir. The amount of chlorine added amounted to approximately $5 \%$ of the total chlorine demand. When the chlorinator was functioning, problems with regulating the dose continued and overdosing was common. As a result, the recommended residual of $1-1.5 \mathrm{mg} / \ell$ in the on-site reservoir was never maintained for any extended period of time during the study period.

\section{Alice distribution system}

The quality of water reaching consumers depends not only on what happens at the treatment plant but also on what happens in the distribution system. Water of the highest quality may be leaving the plant but its condition always deteriorates to some extent before it reaches the consumer. In particular, the protective chlorine residual always decays. Given sufficient time, the chlorine residual will disappear completely. Factors, which accelerate decay, include high finished water turbidity, old pipes, biofilm growth and sludge accumulation in the storage reservoirs. In extreme cases, dangerous re-contamination of the finished water can occur.

Figure 1 shows a schematic of the Alice distribution system developed by the authors with assistance from the municipality's plumbing superintendent. Five of the town's seven reservoirs, including the main reservoir fill up under gravity. Float valves regulate the flows into the reservoirs and they operate at essentially $100 \%$ capacity under normal conditions. Pumping to Ntselamanzi and Mavuso is initiated automatically based on the signals from their level sensors.

Table 1 summarises the average hydraulic retention times of the various reservoirs based on flows measured at the meters shown in Fig. 1. Before October 2003, the Golf Course housing development was supplied from the line to the Mavuso pumping station. From October, it was supplied from the Mavuso Reservoir itself, resulting in a huge increase in flow through the reservoir and a reduction in its hydraulic retention time.

Alice's system of storage reservoirs was obviously designed with future demand in mind and provides much more storage capacity than is currently required. This has a negative impact on the water quality particularly in those areas supplied by the two Happy Rest Reservoirs and in Victoria East. Preliminary water quality monitoring results found that these areas always had low to negligible chlorine residuals and poor bacteriological quality whereas the water quality at Fort Hare, Ntselamanzi and Davidson Primary School (drawing from the Main Alice supply line) was more dependent on the treatment plant performance (Momba et al., 2003a; b).

Two possible options for improving the situation were considered: i) installing booster chlorination in the reservoirs with the lowest chlorine residuals and/or ii) temporarily lowering the reser- 
TABLE 1

Estimated retention times in different reservoirs in the AWTP distribution system

\begin{tabular}{|l|c|l|}
\hline Reservoir & $\begin{array}{c}\text { Estimated } \\
\text { Retention } \\
\text { time (h) }\end{array}$ & Assumption \\
\hline Main reservoir & 60 & Outflow = flow pumped to Ntselamanzi + Fort Hare Line \\
Ntselamanzi & 45 & $100 \%$ full, based on outflow \\
Mavuso - before October 2003 & 306 & $100 \%$ full, based on outflow \\
Mavuso - after October 2003 & 57 & $100 \%$ full, based on outflow \\
New Happy Rest & 151 & $100 \%$ full, based on outflow \\
Old Happy Rest reservoir & 53 & $100 \%$ full, based on estimated flow to Happy Rest \\
Victoria East clinic & 22 days & Based on drop in level in one week when influent shut off \\
\hline
\end{tabular}

voir operating levels to reduce the retention time.

In order to determine the optimum strategy for improving the chlorine residuals, an experiment was carried out to determine the response at various points in the distribution system to a step increase in the chlorine dose at the plant. The sampling points are indicated on Fig. 1. More details can be found in WRC K5/1391 (available by June 2004). The start of the experiment coincided with the restoration of chlorine dosing at the plant after several days during which the chlorination system had been nonfunctional. Consequently, chlorine residuals were low or absent throughout the distribution system. The residual in the in-plant reservoir was maintained at between 1 and $2 \mathrm{mg} / \ell$ free chlorine, depending on the plant flowrate for the first four days.

The experiment was carried out in June 2003 before the line from Mavuso Reservoir to Golf Course housing development was opened. Residuals of greater than $1 \mathrm{mg} / \ell$ were recorded at University of Fort Hare, Davidson Primary and Golf Course within $24 \mathrm{~h}$ of the resumption of chlorine dosing. This confirms that the treatment plant performance is the primary factor determining water quality in these areas. A more gradual increase in chlorine residual was recorded between 20 and $72 \mathrm{~h}$ at Ntselamanzi with a residual of greater than $1 \mathrm{mg} / \ell$ being achieved at the end of the period. This is consistent with the combined average retention times estimated for the Main and Ntselamanzi Reservoirs. It was also evident that the impact of storage time on water quality in this area was small and that the poor quality must be directly related to the treatment plant performance.

The results for areas supplied by Victoria East and Mavuso Reservoirs were unfortunately less conclusive because there had been no flow into the former for a week before the test started and no pumping into the latter for the first four days of the experiment. This resulted in the sudden influx of a large volume of chlorinated water when the flow into the reservoirs resumed. However, the chlorine dosing failed again before the effect of the higher chlorine dose on water quality at Happy Rest, Hillcrest and Forte Flats could be determined.

Regular sampling for chlorine residual and microbial quality were continued at the AWTP, Mavuso Village, Hillcrest, Happy Rest and Forte Flats from July to November 2003. When looking at the trends in the data over the long term, it became evident that

good chlorine residuals and microbial quality could be established and maintained even at the three most distant points in terms of retention time (Hillcrest, Happy Rest and Forte Flats) as long as chlorine was dosed consistently at the plant for a sufficiently long period. This is shown in Fig. 2. The problem with these results was that when the chlorination system was functioning, chlorine was generally being overdosed. Therefore it was not immediately clear that Happy Rest, for example, could enjoy good microbial quality without central Alice, the University and Ntselamanzi Village suffering from excessive chlorine levels.

In order to resolve this issue, it was first necessary to establish the minimum residual required ensuring acceptable microbial quality. Figures 3 to 6 show the microbial quality results plotted against chlorine residual and compared with the guidelines for drinking water quality (DWAF, 1996). It appears that the guidelines for microbiological safety can generally be met if a residual of at least $0.3 \mathrm{mg} / \ell$ is maintained at all points in the distribution system.

It was found that if all the results in Fig. 2 were scaled down by a factor of 2.2 then most of the in-plant residuals fell with the range 1 to $1.5 \mathrm{mg} / \ell$ while the residuals at the sampling points remained above $0.3 \mathrm{mg} / \ell$. If the decay of the chlorine is assumed to be approximately first order, then the chlorine concentration in water at any point in the distribution should be proportional to the its chlorine concentration when it left the plant. Therefore it appears that the chlorine residual can be maintained at a reasonable level in all sites without booster chlorination.

Based on these results, it appears that not only is booster 


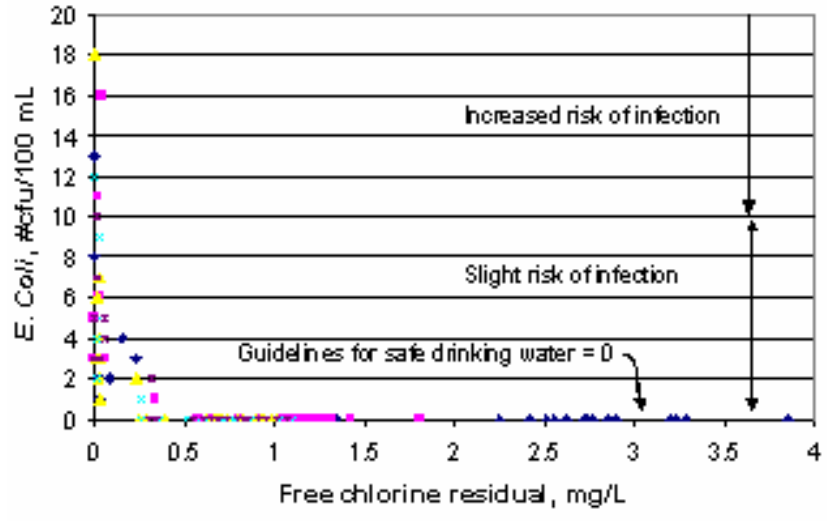

+h-plant " Mawso Wlage Happu Rest * Forte Flats : Hillcrest

Figure 3

E. coli counts versus chlorine residual July-November 2300

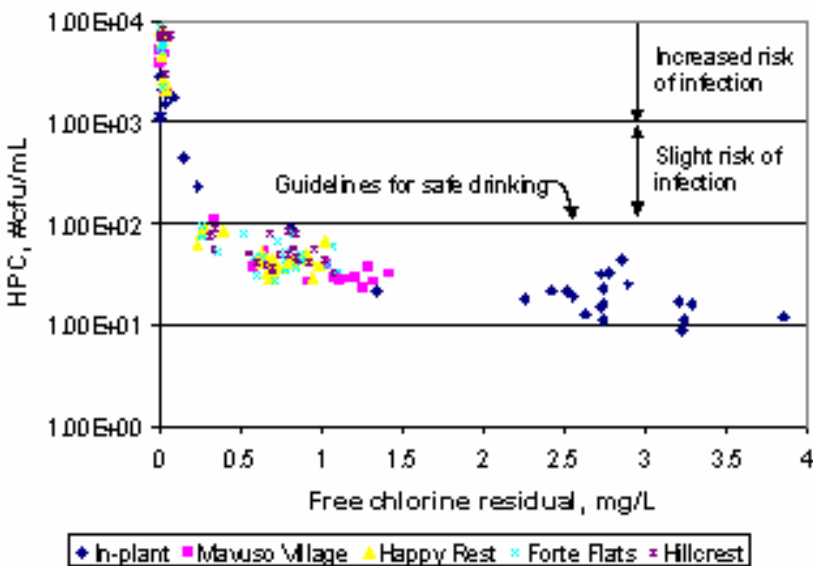

Figure 5

Heterotrophic plate counts versus chlorine residual

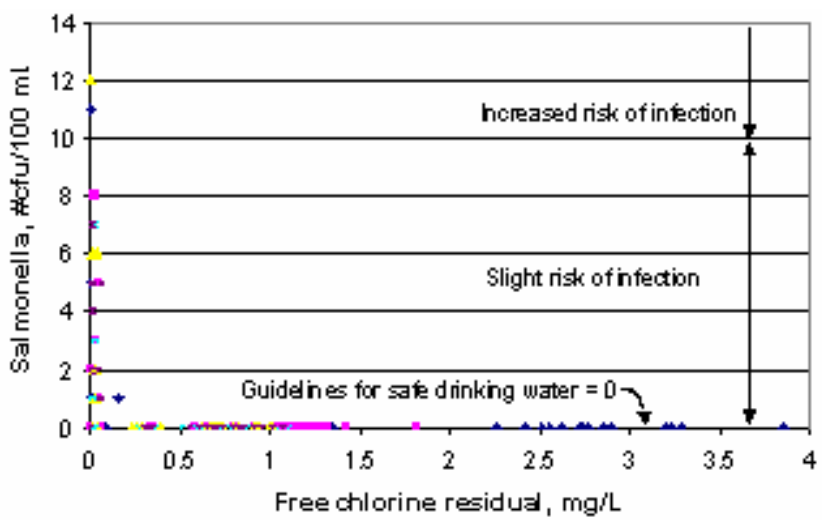

$+h$-plant = Wawso Wlage Happy Rest $\times$ Forte Fats $x$ Hillcrest

Figure 4

Salmonella counts versus chlorine residual July-November 2300

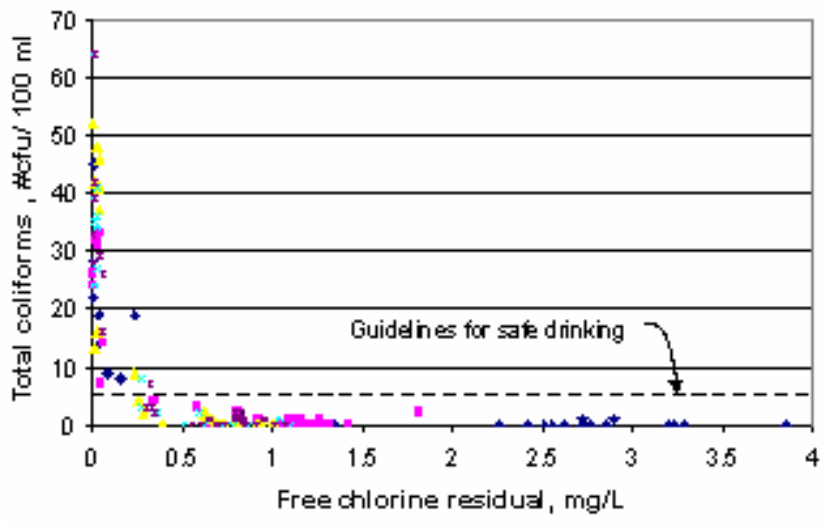

$+h$-plant = Mawuso Wlage Happy Rest $\times$ Forte Fats $x$ Hillcrest

Figure 6

Total coliform counts versus chlorine residual July-November 2003

Programme (MMP) came up as a possible solution to this problem. The AWTP did not have a large pool of trained engineers and scientists to deal with constantly changing treatment. Umngeni and Pollution Research Group have extensive prior experience in water treatment and could provide the initial training and guidance on improving the plant operation. The Fort Hare group would then provide ongoing support for the operators and performance monitoring. Although there were some misunderstandings between the project team and the municipality at the beginning of the project, co-operation played a large role in plant improvement. The operating staff at the AWTP had previous experience in the day-to-day running of the plant. However when the project started, they lacked the knowledge and confidence to improve the plant. Their involvement with the research team seemed to improve their confidence and understanding of water treatment.

The research team conducted a three-day operator-training course in November 2003. At this time, the operators already had a reasonable qualitative understanding of the treatment course so the course focused on quantitative issues. The training included the following: 1) how to measure the water level over the $V$-notch weir and convert it into a flowrate, 2) the jar test for determining optimum Ultrafloc dose, 3) the chlorine demand test and 4) understanding the operation of the valveless filters. The operators did not appear to have the confidence to a use a calculator so a system of tables was developed which would allow them to 
determine the raw water flow from the $\mathrm{V}$-notch measurement and the correct coagulant and chlorine dose rates for any given flow from the results of the jar and chlorine demand tests.

The operators were very appreciative of the training and stressed that the relationship between the project team and the operators should be one of the mutual co-operation and support. At the time, it was pointed out that no improvements in plant performance would be possible until the dosing equipment was repaired and the filter problems attended to.

\section{Achievements and continuing problems}

Improvements have been made in the AWTP, however there is a lot of room for improving monitoring, maintenance and enforcement to protect AWTP water quality.

When the project started, there was no water quality monitoring done by the municipality and no records were kept concerning the operation of the plant and the operators lacked knowledge in improving the plant. During the second phase, records on turbidity measured at different stages of treatment together with the chlorine residual results were found in the plant. The operators were quite confident and knowledgeable about the operation of the plant. This improvement was brought forth by the cooperation with the research team and the training that was provided by the former MMP staff member.

At the time of writing, the plant was still having problems with the chlorination system, however, steps were being taken to repair or replace the leaky chlorine regulator. The method of adding HTH to the finished water when the chlorinator was off-line had improved somewhat with powdered form being added to the reservoir every two hours instead of once a day. The coagulant suppliers had replaced the faulty coagulant pump and arrangements were being made to get a standby pump. The Municipality was taking steps towards having the filter media replaced and the filters services. They were also looking into purchasing the jar testing apparatus.

\section{Guidelines and recommendations}

\section{Clarifying roles}

There needs to be a clear framework clarifying roles and responsibilities for all the various stakeholders who are engaged in ensuring the safety of drinking water in AWTP and in other small water treatment systems. Equally as important is the need for the municipal management structures at all levels to support this framework by making the provision of adequate resources to fulfil these various roles.

\section{Tools for operators}

Mechanical tools and suitable instruments should be made available to the operators. Competent people and good equipment are necessary for safe drinking water.

\section{Maintenance}

Staff should be trained for the proper maintenance of the water treatment plant and a plan for regular maintenance system should be drawn up. The municipality should ensure that there are functioning standby parts like coagulant dosing pumps and chlorine dosing systems. Emergency response plans should be made.

\section{Chemicals}

The problem of frequent and prolonged coagulant and chlorine disruptions in AWTP needs to be solved immediately as it is the main cause of inadequate disinfection.

\section{Communication}

A better communication between the operators and the management is important. A co-ordinate emergency response strategy should be developed collaboratively to identify clear roles and interrelated response mechanisms. Broad based communication of water quality and awareness information to restore public confidence in drinking water should be a significant area of communication activity.

Communication with the customers is vital when there are problems in the plant, not only to ensure that notice of the boil water is quickly given but also that they understand the problem, the risks, what the municipality is doing to rectify the situation and what measures are being implemented to minimize the problem.

\section{Acknowledgements}

The authors wish to thank the Water Research Commission of South Africa who sponsored this investigation. The assistance of Mr Koot Kruger of Sudchemie and Mr Thabo Marala of Nkonkobe Municipality is also gratefully acknowledged.

\section{References}

BROUCKAERT BM, PRYOR MJ, PILLAY P, ZONDI TA and AMIRTHARAJAH (2002) Assessing the use of autonomous valveless filters for turbidity removal in rural applications. Proc. of IWA Biennal Conf. and Exhibition, Durban. 19-23 May.

DEPARTMENT OF WATER AFFAIRS AND FORESTRY (1996) South African Water Quality Guidelines for Domestic Use ( $2^{\text {nd }}$ edn.) Pretoria. $197 \mathrm{pp}$.

MACKINTOSH G and COLVIN C (2002) Failure of rural schemes in South Africa to provide potable water. Environ. Geology 1-9.

MOMBA MNB and KALENI P (2002) Regrowth and survival of indicator microorganisms on the surfaces of household containers used for storage of drinking water in rural communities of South Africa. Water Res. 36 3023-3028.

MOMBA MNB, NDALISO S, BINDA MA and MAKALA N (2002) Inhibition of Biofilm Regrowth in Potable Water Systems. WRC Report 1023/1/02, Water Research Commission, Pretoria.

MOMBA MNB, MAKALA N and BROUCKAERT BM (2003a) Evaluation of the factors affecting the performance of small water supplies for the removal of indicator bacteria in rural developing areas of South Africa: case study - Alice water treatment plant. International Water Association (IWA) Conference, Health-related Water Microbiology Symposium, Cape Town, South Africa.

MOMBA MNB, TYAFA Z and MAKALA N (2003b) Rural water treatment plants fail to provide potable water to their consumers: Alice water treatment plant in the Eastern Cape Province of South Africa. S. Afr. J. Sci. 100 307-310.

MUYIMA NYO and NGCAKANI F (1998) Indicator bacteria and regrowth potential of the drinking water in Alice, Eastern Cape. Water SA 24 (1) 29-34.

SWARTZ CD (2000) Guidelines for the Upgrading of Existing Small Water Treatment Plants. WRC Report No 738/1/00, Water Research Commission, Pretoria. 